other and successively smaller clouds were formed directly under the first, having symmetrical and concentric outlines therewith, while the central vertical axis, which might be conceived as passing through the whole series, remained unchanged and fixed in space. This central fixity, too, of them all continued, together with the infinite smoothness of the outlines of all the smaller lower strata of cloud, although the largest and uppermost one visible to us began to put forth a variety of fringes of cirro- cumulous character ; and, as tested by the spectroscope before sunset, all the lower smooth-rimmed clouds were remarkable for the large quantity of watery vapour they contained, and held fast too, for no rain fell. As sunset approached every one was gazing at the strange phenomenon of a cloud-congeries of most portentous size and absolute fixature above the trade-wind, probably also the anti-trade region; and after sunset the most gorgeous coloured illuminations through all the ranges of scarlet-red, red, crimson-red, ultra-red; and then dun-coloured and grey passed from member to member of the series, distinguishing the various heights of its strata one above the other; while the greatness of the general height was shown, even long after darkness had set in, by a faint lunar-like illumination of the northern outline of the whole. But by ten o'clock that began to fail, and the system of superposed clouds was beginning to contract on its central axis, and faded away, without leaving its place, before morning.

In so far we had been witnessing, though without any positive light of its own, a vertical series of disks of cloudy matter, extremely like the lower end of the successive, transverse, discous arrangements seen in a gas vacuum-tube of large dimen. sions, when the electric discharge from a powerful induction-coil is passing through it; and we were inevitably reminded thereby that the cosmical electric theory of $M$. Gaston Planté (of "secondary batteries or storage" fame) justifies an escape of the earth's interior electricity from time to time into planetary space, and more particularly to the sun.

Was there, however, in this case any symptom of the sun exciting, or calling for, any such discharge, and from this part of the earth?

The sun was undoubtedly in the Northern Tropic, and the highest northern declination for the year had just been reached but for a fortnight or more past the solar spot manifestations had generally been weak, almost fading away. This I knew well, having taken a picture of the sun-spots every day (Sundays excepted) since I have been here. However, though the appearances were as poor as they well could be on June 21,22 , and 23 , yet on Friday, June 24, there was a little improvement, some new, though small symptoms appearing in either solar tropic. On Saturday, June 25, these new features were confirmed and slightly increased. But what were they on Sunday, June 26, when the extraordinary cloud-arrangement was hanging so long above Madeira?

I, who am here merely as a private amateur in a different sub ject, know not; but on Monday morning, so early as $5 \mathrm{~h} .3 \mathrm{om}$. a.m., I was astonished and delighted at the solar scene then presented. The spots first caught sight of on Friday were now well advanced and much developed; a new group with extensive double ramifications had also appeared in the same tropic nearer the equator; while finally, near the middle of the sun's disk in the south tropic, were two large spots, with connections extending over 60,000 miles in length of solar surface, and indicating more solar energy to have been thereby rapidly, if not suddenly, manifested within the last forty hours, than anything which I, at least, have witnessed for a very long time past.

FiazzI Smyth,

Jones's Hotel, Quinka do Corvalho,

Funchal, Madeira, June 27

P.S.-The grand, and now circumpolar, comet was not neglected here on the same night. - P. S.

\section{Carbonic Acid Gas not Free in Sea Water}

IN a short paragraph in NATURE, vol. xxiv. p. 176 , it is stated that Tornö, in the Norwegian Deep-Sea Expedition, had found "carbonic acid both in a gaseous and basic form."

For some time past I have doubted whether there was any free carbonic acid gas in the deep water where pressure should make its presence felt. Lately, in a paper to the Royal Microscopical Society, I have demonstrated that if there is any carbonic acid in the sea water at great depths, its dissolving action is not equal in rapidity and intensity to that exercised by $a$ microscopic Thallophyte which bores into an bissn'ves sponge spicules from within. Moreover amongst dech sea deposits I find perfect organisms which have long been pead, wisich have been penetrated by parasites and covered hece and there by foraminifera, and yet in exposed parts, the ornamentation is perfect. There is no evidence of erosion.

Now on carefully examining into Tornö's essay come to a different conclusion to the writer in NATURE, and I 1 nd that the able Scandinavian denies the existence of free carbonic acid in the sea.

The following notes, which I made in abstracting Tornö's "Chemi" of the Norwegian North Atlantic Expedition, Part II., may be interesting :-

The carbonic acid gas, driven off by the process of boiling sea water, when collected, varied in a most marked manner; it was always appreciable, and the quantity was sometimes large. The pressure was that of the atmosphere. Under different conditions, and when the gases were boiled out in a vacuum created by steam, and of course at a lower temperature, the quantity of carbonic acid gas was often immeasurably small. Moreover the quantity varied.

Jacobsen, by distillation, succeeded in expelling the whole amisunt of carbonic acid contained in a quarter litre of sea water, and found that North Sea water contained $100 \mathrm{mgr}$. per litre. The neutral carbonates in the residuary deposit contained about Io mgr. per litre. Hence a very small proportion of the carbonic acid driven off by distillation, could have been present in bicarbonates. Vierthaler had asserted that the carbonic acid in sea water was got out of the bicarbonates by boiling.

If the carbonic acid is free and absorbed by the sea water in a free gaseous form, it is remarkable that it should not be more readily got. Jacobsen supposed that sea water has a peculiar property of retaining its carbonic acid, owing to the presence of the chloride of magnesia. Buchanan was led to believe that most of the salts were in some degree distinguished by the property of determining the retention of carbonic acid in the sea. He especially insisted on the importance of the sulphates, and asserted the meen amount of carbonic acid present in the waters of the Southern Seas to be 43.25 mgr. per litre.

Tornö, following Jacobsen, found the amount of carbonic acid gas present in the water of the track of the northern cruise of 1877 to be about $100 \mathrm{mgr}$. a litre, but got $12 \mathrm{mgr}$. per litre as a variation in the amount.

$\mathrm{He}$ was struck with the improbability that sea water should possess so remarkable a power of retaining mechanically one gas and exert no corresponding influence on others, and then he found that sea water had an alkaline reaction. He began to believe that some of the nentral carbonates had been decomposed during the boiling, and had evolved much of the carbonic acid gas.

He then proved by experiment that the saline mixture in sea water, on the temperature being raised to the boiling point, decomposed neutral carbonates, and that all previous experiments with the object of measuring the carbonic acid in the sea water had been faulty. He was influenced by some experiments on the determination of carbonic acid gas in mineral water, and applied the method to sea water.

$\mathrm{He}$ found the total amount of carbonic acid gas in a specimen to be 97 mgr. per litre, and the proportion forming neutral carbonates to average about $53 \mathrm{mgr}$. The difference, $44 \mathrm{mgr}$. cannot occur free as gas, but will unite with the carbonates to form bicarbonates. Hence Jacobsen's experiments could be explained on the $\mathrm{s}$. umption that sea water contains no trace of free carbonic acid, but as much as $53 \mathrm{mgr}$. per litre forming carbonates, and only $44 \mathrm{mgr}$. forming bicarbonates.

On page 35 he states: "If we bear in mind that sea water is an alkaline fuid which does not contain the smallest trace of free carbonic acid."

What a comfort this must be to globigerina and coral reefs ! June 27 P. MARTIN DUNCAN

\section{Symbolical Logic}

I AM afraid I share the proverbial obtuseness of my countrymen in the matter of jokes. I really did not at first see the point of Mr. Venn's humorous suggestion that "an attitude of slight social repression" should be observed towards troublesome 2uthors of new proposals. Now however that Mr. Venn has kindly pointed it out to me (see NATURE, vol. xxiv. p. 140), I see the joke perfectly and can laugh at it heartily. 